\title{
Intellectual potential as a means of reproduction and renewal of the unity of productive forces and industrial relations
}

\section{Sergey Voit*(D), Vladimir Tkachenko**(D), Irina Oleshkevich***iD}

* Alfred Nobel University,

18 Sicheslavska Naberezhna, 49000, Dnipro (city), Ukraine

Dr, Professor

** Alfred Nobel University,

18 Sicheslavska Naberezhna, 49000, Dnipro (city), Ukraine

Dr, Professor, Research Institute of Economy and Society Development

*** Ukrainian State University of Chemical Technology,

8 Gagarina Ave., 49000, Dnipro (city), Ukraine

M.A., Department of Economics

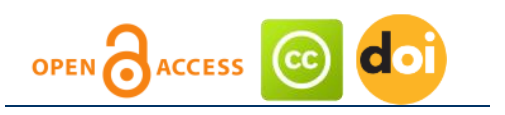

Article history:

Received: January 18, 2018

1st Revision: February 15,

2018

Accepted: March 15, 2018

\section{JEL classification:}

032

L16

L52

DOI:

10.14254/jems.2018.3-1.3

\begin{abstract}
The conceptual view on the unity of productive forces and industrial relations in modern social structures of production expressing the active relation of people to the accumulation of material goods as an indicator of the spiritual development of the social structure has been presented in the work. It is proved that the technological basis of society is a state priority of structural changes in the economy, which determines the rates of economic growth regardless of the level of development. The new paradigm, which was called "technological method of production" as a dynamic system of not only production forces, but also of technological production relations, due to the optimization of internal production processes transformed into a system of technological relations, the nature of which is determined by the nature of the operation or transition in the technological process, has been conceptually substantiated.
\end{abstract}

Keywords: production forces, production processes, social structure, technological method of production, transformation, technological innovations, structural changes. 


\section{Introduction}

If we adhere to the canons of classical theory, then we can say that "productive forces are a system of subjective (human) and material (means of production) elements that reproduce the active attitude of people to nature, which consists in its material and spiritual development and development of its wealth (values), in the process of which the conditions of human existence are reproduced and the process of man's development is being fulfilled".

The beginning of the XXI century has reflected new socio-humanitarian transformations that require new approaches to the definition of the content and quality of productive forces. The latter should not only outline, but also give rise to the priority parameters of the global socio-ecological and spiritual order of the modern world and determine the technological shifts that would form the basis for further economic development. There is no doubt that the key role of the technological basis in the process of economic growth in most countries of the world is their state priority of structural changes in the economy. At the same time, the sphere of influence of science-based technologies is limited not only by the system of economic relations, but also by such social and public levers as GDP, industrial output, employment (the magnitude of unemployment), labour productivity, the reliability and durability of technological equipment. The above sphere is also limited by the content of the social structure, which, in its turn, is formed and exists under the influence of technological novations.

There is no doubt that it is the technological basis of the society that determines the growth rate of economy in most countries of the world, both those considered to be leading and more developed, and those that are only at the beginning of great shifts. It is in today's approach that a new concept emerged, which was called "technological mode of production" as a dynamic system of technological relations. It is believed that at present, industrial relations due to optimization of internal production processes have been transformed into a system of technological relations, in which the nature of their internal content is determined by the nature of the operation or transition in the technological process. It is thanks to successive changes in the technological method of production that the nature of technological development is determined. These changes also influence structural changes in the economy in general, which makes one system of technological relations, based on the dialectics of internal processes, pass to another. Thus, natural transformation of the entire social structure takes place.

\section{Materials and Methods}

The key role of technological factor in the process of economic growth in most countries of the modern world is materialized through the system of state technological priorities. These form and renew the technological basis of society and transform the system of technological relations, which, in turn, determine the nature and strategy of social and economic growth of a society of this or that structure ("Great economic dictionary," 1999).

Determining the multidirectional character of research and design developments in the field of technological base renewal we should note that the questions of their economic essence, determination of their value and intellectual property as an element of the national wealth of the country, as the nature of technological relations both in the field of productive forces and in the field of industrial relations remain the least investigated (Tugan Baranovsky, 1994).

Productive relations of the present are a set of technological, technical and economic relations between members of the social formation formed in the process of production, depending on its nature and level as well as property relations, thus determining the technological basis and socio-economic structure of society.

This relationship should be considered not only as interaction between people who are the main chain link (more precisely, mechanism) of relations in the socio-economic system, but also as the appropriate interaction between social formation and Nature (Tkachenko, 2007). The materialization of these interactions forms a new concept of the technological basis of society (its productive forces) and provides dynamic development of intellectual potential, which, in turn, determines the nature of the technological basis of production through the consistent realization of knowledge and changes in productive relations (Lyashenko, 2006).

\section{Goal of Research}

Thus, we obtain the possibility of designing the concept of regulatory parameters for the development of models of socio-political and socio-economic systems. The models involved can simultaneously take into account the production potential of society and the productive relations of 
people, technological basis, socio-political and socio-economic background, environmental subjective and personal factors of social formation, an integral part of which is the moral and spiritual imperative. At the same time, the progressive development of social formation of any civilization is the basis of socio-economic regularity of the socio-cultural dynamics of development. This suggests that such a type of complex self-development systems cannot be considered apart from other, even minor, factors as well as external influences or individual approaches.

\section{Results}

The scientific and technological revolution of modern times offers the way to a natural civil society and social production, technologically incomparably more complex than that of the past, or even modern in the most developed countries. The requirements for professional competence and social responsibility are increasing. This refers not only to those who work in one or another sphere of production, service, socio-cultural branch or education and health, but to all members of society, even children and infants, as components of the general intellectual and socio-cultural potential of social formation. Besides, the exchange of productive, social and economic information based on the totality of the technological base, is becoming more profound, meaningful and multifaceted. In order to operate successfully such complex socio-economic self-developing social system needs a universal, well-trained worker or employee who has knowledge of his profession and scientific knowledge of the world.

The present recognizes that innovative activity in the field of improving the technological basis for complex self-developing socio-economic systems is one of the strategic factors of development, the main factor of the strategy of both the state on the whole and individual enterprises of different subordination and forms of ownership (Nagornyak \& Vovk, 2012). It must be emphasized that not economic indicators and social factors (they appear to be derivatives) but technical and technological potential of productive forces forms the basis of the decline and growth of the national economy. That is why the main factor in the functioning of complex socio-economic self-developing systems is not static competition between the market participants or countries but the potential of productive relations through competition from new products or services based on new technologies. These technologies are regarded as the result of the creative use of the aggregate potential of society, industry, enterprises, and firms. It is the innovation activity through the improvement, production, introduction and use of advanced equipment at the enterprises that creates the necessary conditions for searching and developing the latest technologies. The latter, in turn, transform productive relations through the systems of production organization and improved methods of its management. Thus, we can say that the process of continuous and accelerated technical, technological and organizational renewal of social production through the transformation of productive forces is irreversible factor mobilizing intellectual potential in the restoration of industrial relations.

It should be noted that the physical actuation of technical means of production recedes into the background in comparison with the moral aging of the knowledge embodied in it. For several years of use, and sometimes even during the construction (creation) of an enterprise, which has to manufacture different apparatus, and equipment and technology aging takes place. The process involves not only the knowledge embodied in the technological equipment, in the productive forces in general, but also living knowledge, whose bearer is the creative initiative activity of each person. This fact cannot but affect the production relations.

In the continuous cycle of updating the objective (material) and subjective (personal) production forces, the scientific and technological revolution at each of its transitions transforms the production relations. In the present, it has introduced an unprecedented inversion: for the first time in the history of socio-economic development, the rate of technology generations changes (production forces) has rapidly surpassed the rate of changes in generations of workers and employees (production relations), which cannot but cause disproportion of renewal and development. Now, during the life of one generation of people, during their labour activity, in the advanced branches of social production, there occurs a change of several generations of technology, which significantly influences the transformation of production forces. This process changes the socio-economic essence of society transforming productive relations. Unfortunately, social consequences of scientific and technological development are not fully recognized by the general public and also by the state institutions and the majority of scholars. Meanwhile, the problems of socio-economic reformation, both in our country and abroad, need urgent awareness and scientific research. The results of scientific research over the past 5-6 years confirm that without understanding the theory, without clarifying the concepts of economy, technological organization of production and management, it is impossible to solve the practical question of improving interaction between production forces and industrial relations. 
Considering the historical and graphic cycles of social development of people, we can notice that the industrial revolution did not give rise to the original material means of production from nothing (in the absence of samples). Likewise, the scientific and technological revolution did not create the productive force of knowledge in a vacuum. In essence, the former revolution transformed hand tools into machines and primitive craft into fabricating industry. The former, together with empirical knowledge and enriched experience, transformed systemic use of intellectual potential into individual creative economic activity. It should be stressed that without this potential it is practically impossible to identify the productive forces and production relations. The main consequence of these two revolutions is that they not only foresaw the opportunities, but also prepared the basis for the third type of the revolution - the intellectual one. The essence of this revolution is the use of total intellectual potential as the fundamental principle of social development. This approach forms the basis of a new direction of philosophical thought - the philosophy of socio-economic relations in the conditions of instability and unpredictability of the social development dynamics. The above mentioned approach should be considered in terms of theory of complex self-developing socio-economic systems.

Principally important distinctive properties of the functional processes of self-organizing systems lay in the fact that on the background of a monotonous increase or decrease in parameters of the system, sudden unexpected changes in its state may occur. The system is influenced by bifurcation processes, which is inherent in a catastrophe due to nonlinear relationships between elements and processes.

Usually, for open systems with inverse relations, similar disastrous state is usually much more complicated than the usual bifurcation process with catastrophic consequences. After passing the state of bifurcation, the further evolution of the system ceases to be unambiguous: it operates according to one of the alternative scenarios that are significantly different. The behavior of such a system, after passing the boundary of the catastrophe, becomes paradoxical, as if it were split. Moreover, in the activity of these directions randomness, secondary factors, with energy doubled by the governing institution, its human potential of intelligence begin to acquire the fundamental role (Leskov, 2001). It is precisely in this condition that our state remains as a large self-developing social system, where the secondary influential processes of political parties and certain miserable politicians play a dominant role. It is they who now play a major role and have a decisive influence on the transition of the system to one or another evolutionary, as a rule, artificial, false scenario. And this happens only because in the realm of the critical point, nothing and nobody interfere these minor far-fetched processes. This means that the socio-economic, political and cultural system has lost its stability, has left the regime of self-government.

In everyday life, people more and more often face the situations that require a new level of knowledge of the possible and awareness of the necessary for the adoption of skilled, optimally effective managerial decisions that will help to find proper way out. The experience of knowing the possible and level of awareness of the necessary cannot be determined by quantitative indicators it is more a kind of bioenergetic informational substance that envelops us, directs us, improves us, makes us live in any conditions while the program complex of each of us - the brain - functions.

Having studied the experience of the past centuries, we consciously understand that the prosperous existence of each country, its development, as well as the development of this or that social structure was historically formed at the level of using natural, labour and material resources in the total intellectual potential of these countries. Predicting the future, we are convincing ourselves that these resources are losing their significance with each step forward.

Only the aggregate intellectual potential of society together with the level of total knowledge of the social formation is increasing. Today, not only highly developed countries, but also those that are trying to become them, compete more and more not for the quality of commodity products, which is also of great importance, but for the level of society's aggregate knowledge. This becomes a new "battlefield" for both countries and for their subjects of production.

In the study of the problems, an important role belongs to the theoretical understanding of the initial categories and concepts, which, in a certain sense, have become traditional for the economic science. The decisive role is played by the following concepts:

- socio-economic environment, which is understood as a set of socio-economic processes occurring in a certain time and space;

- social sphere, which is understood as a set of elements: the individual (subject) of the initiative economic activity; socio-economic formation; natural processes occurring in a confined space whose probability of consequences has to be determined by the density of economic entities and the amount of the natural potential.

Among these categories are labour resources, that is, a certain part of the working age population. This indicates that there is a quantitative approach to the concept of labour resources 
that are considered as a set of individuals with account taken of demographic characteristics (sex, age).

Labour resources are an independent economic category. At the same time, they are the initial demographic, economic, sociological and statistical categories of the corresponding scientific disciplines, because labour resources are a part of the population that has the necessary development, health, culture, skills, qualifications, professional knowledge for working in the field of socially useful activity. This population is in working age, and partly is beyond it (working teenagers and pensioners).

The study of the effective use of labour resources, in respect of industrial relations, is carried out at three levels: macrolevel (country); mesolevel (region); microlevel (town). Macro level is known to have been studied profoundly. The processes of employment at meso and microlevel are the least studied.

According to their place in social division of labour and functional role, settlements are divided into urban and rural ones. The life of the population in cities is connected with the functioning of industrial enterprises, construction objects, transport and social infrastructure, etc. In rural settlements, population activity deals with the use of land, development and location of agricultural production. According to this, population, which is the natural basis for the formation of labour resources, depending on the place of residence is divided into urban and rural.

Dnipropetrovsk region is one of the key regions for ensuring effective employment in the country (its labour resources account for $8 \%$ of the total). About $75 \%$ of the region population lives in cities, $9 \%$ - in urban settlements, the rest (nearly 16\%) - in villages. The distinguishing feature of the region is the presence of several large technopolises: Dnipropetrovsk - 1094 thousand people, Krivoy Rog - 697 thousand, Dniprodzerzhinsk - 267 thousand, Nikopol - 148 thousand, and Pavlograd - 125 thousand, which make 63.4 percent of the region's population.

On the one hand, these technopolises are characterized by a high concentration of industrial facilities, by the development of social infrastructure, transport networks, industrial and social communications that ensure their attractiveness for migration flows. At the same time, they are characterized by intensive anthropogenic pressure on the environment, degradation of demographic processes, deterioration of the quality of labour potential.

In Ukraine, $68.04 \%$ of the total population is concentrated in cities. This is due not so much to more comfortable living conditions, but due to the development (as a result of industrialization) of agglomerative forms of resettlement, which have better conditions for the implementation of most areas of human activity and improvement of the ecological state. Therefore, large cities are effective in terms of the economy, the forms of functioning of production activities. Conveniences are still crucial in the formation of the population lifestyle. Therefore, 33.5 million people are known to live in urbanized areas, which contribute to the penetration of urban relations into rural settlements, as well as to the expansion of the sphere of labour employment. Consequently, cities occupy a special place in the development of the economy and public life of the country. Problems of the complication of the labour market functioning in the new economic conditions are characteristic of all the cities.

One of the problems associated with reforming the Ukrainian economy is the problem of the efficient use of labour resources as the main element of production, which functions not in isolation, but in inextricable connection with other elements. Therefore, increasing the efficiency of the use of labour resources should be considered an integral part of an overall process of social reproduction.

Considerable difficulties in the study of labour resources as relations of production arise due to the uniqueness of the object of research. First, this object has the ability to self-reproduction not only at the previous, but also at much higher quantitative and qualitative level. Secondly, the object involved has the ability to change substantially its behaviour refuting many forecasts and calculations. In this capacity it can be classified as a category of weakly determined objects. However, labour resources - production relations - cannot be considered an unguided object. Thirdly, in the practice of employment regulation, we must proceed from the assumption that influence can be effective only if it is rightly oriented towards the interests of the overwhelming majority of the population, because economic interests are a form of economic laws manifestation.

Despite the growing attention to labour resources, Ukraine has not yet created a single regulatory system that can ensure the efficient use and reproduction of labour resources."... Although in recent years the rights and obligations of labour bodies have been considerably expanded, but until now, no system of organizational, economic, legal measures, and in general an economic mechanism has been created that would allow the formation, distribution and rational use of labour resources." (Bulgakov, 1999), in other words," ... in the theoretical as well as in the applied direction a harmonized system of labour resources management has not been developed 
yet... " (Tkachenko, 2008). Therefore, labour resources are proposed to be considered as a large open socio-economic system (Fig. 1).

Figure 1: Scheme of regulating the influence efficiency on productive relations

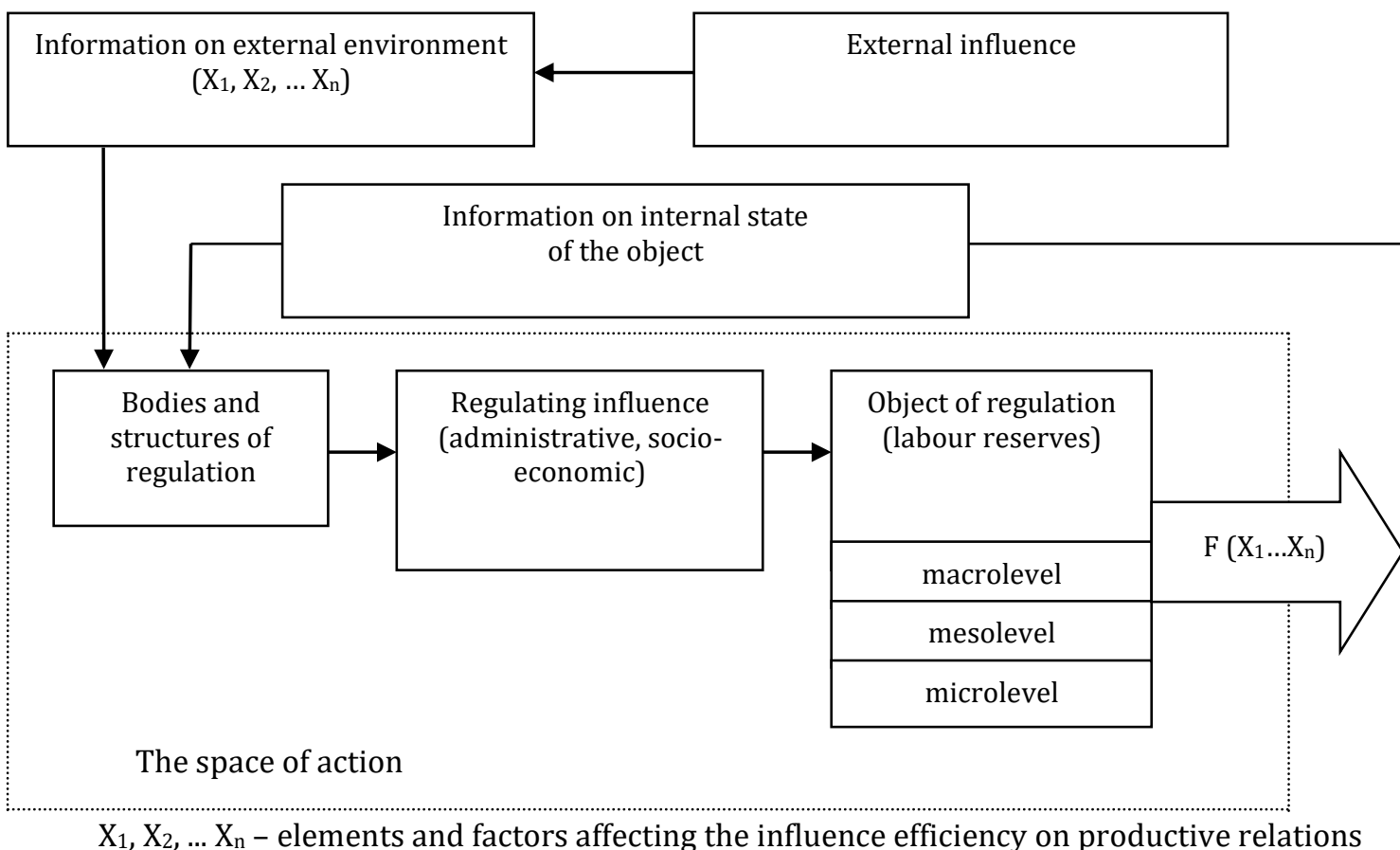

In accordance with the principles of the general theory of systems, we can construct an abstract scheme of the object being studied. The object under investigation - labour resources - is a system object formed by able-bodied people of urban and rural population (Fig. 2).

\section{Figure 2: Scheme of labour resources regulation}

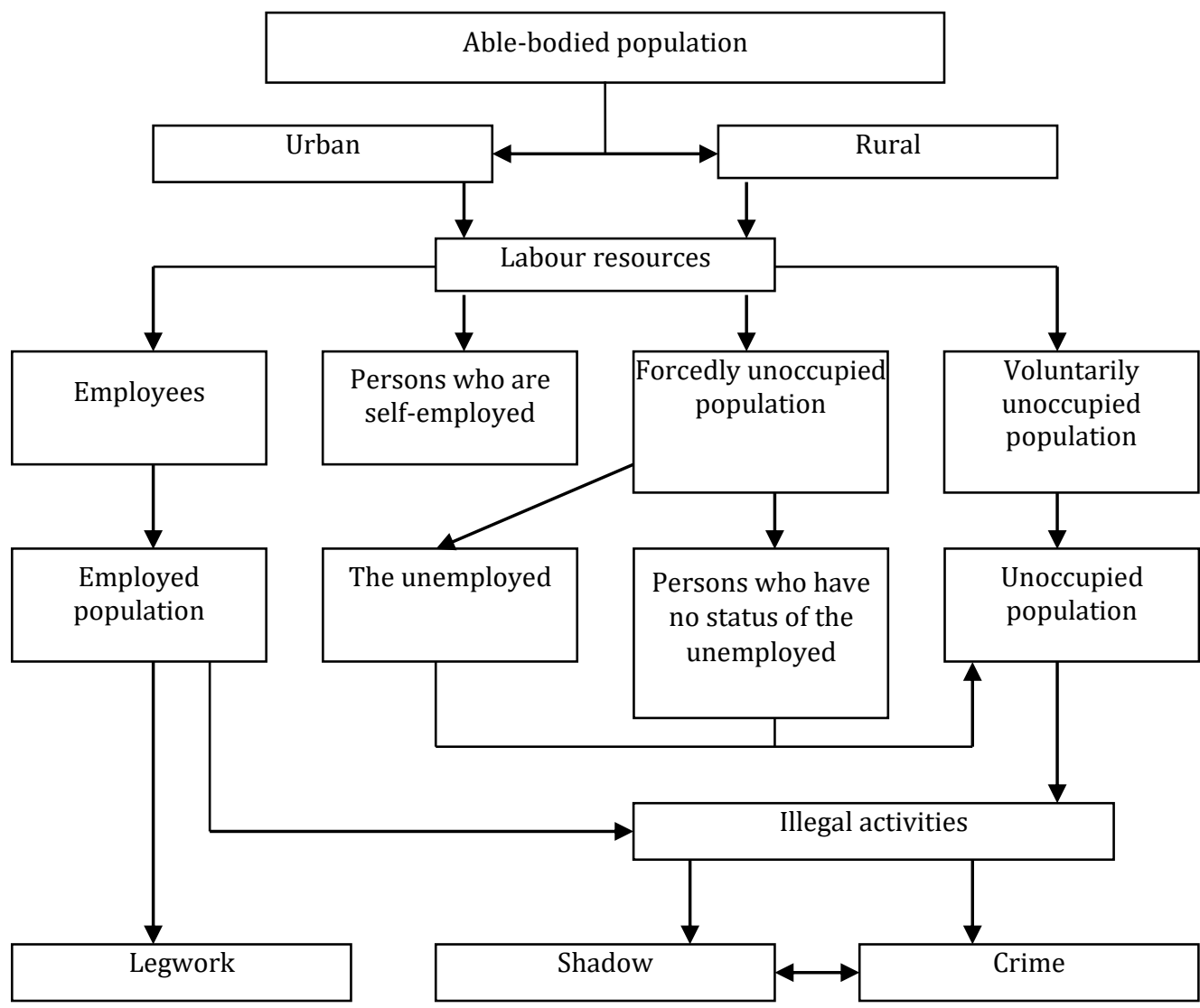


Urban employment as a complex system can be represented as three interconnected blockssubsystems (Figure 3):

block 1 - employment differentiation according to the form of working time organization;

block 2 - employment differentiation according to priority and sphere of labour application;

block 3 - differentiation of employment in relation to its legality (registered and unregistered) and by its consequences.

In accordance with existing forms of ownership, it is possible to identify two principal areas of the population labour application - state and non-state one.

The main distribution involves the separation of registered employment from unregistered one (block 3).

Figure 3: Differentiation of urban population employment by main blocks-signs

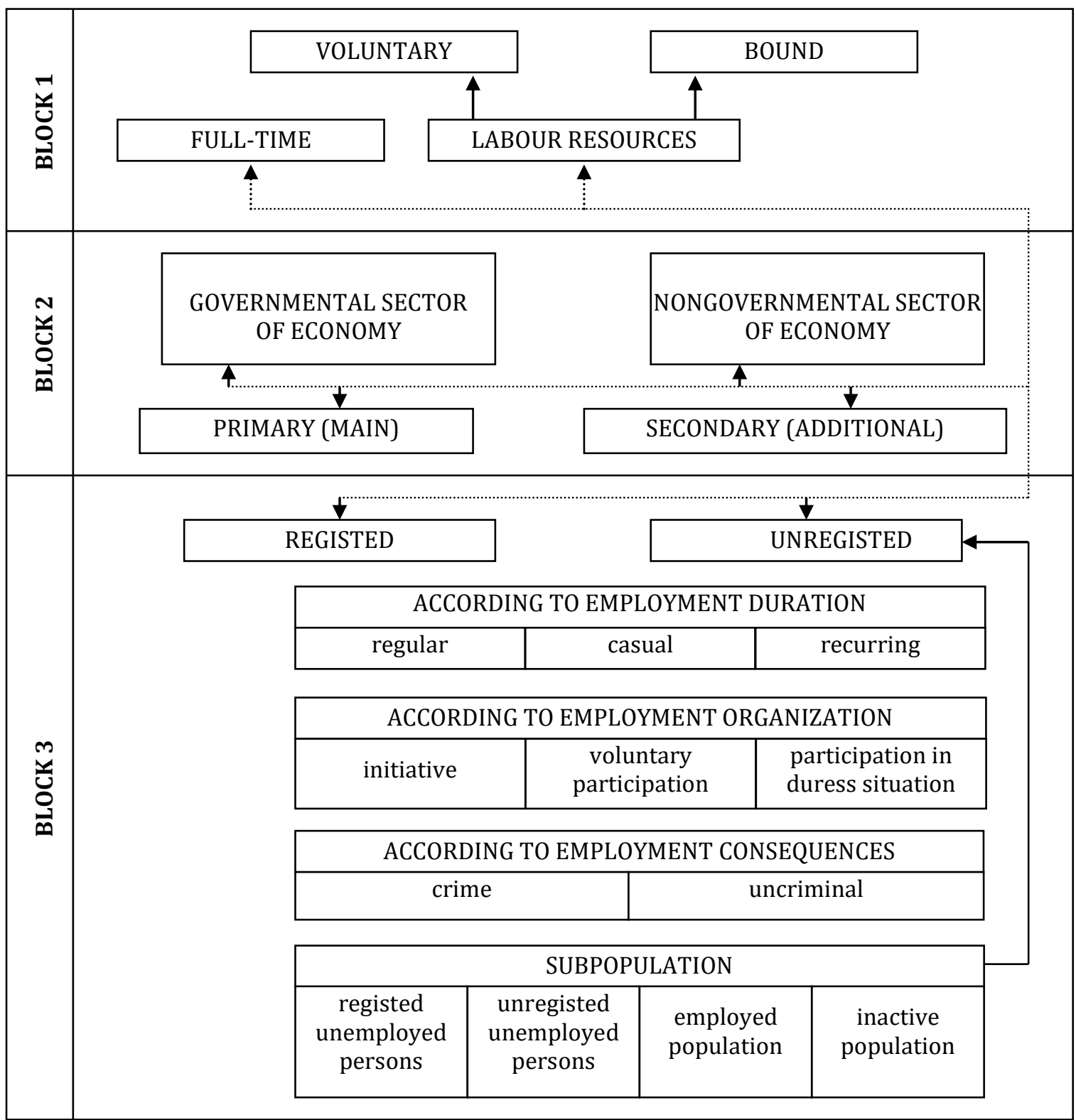

Employment may be registered (if a company is a registered legal entity and submits statistical reports timely) and unregistered (if for some reason a company evades registration).

Economic reforms that have been taking place in Ukraine since the early 1990s have created a number of new phenomena in the field of employment. These include underemployment and illegal (shadow) employment. There is no clear definition of the concept "illegal employment" so far. The main feature of the illegal sector is the lack of registration and non-payment of taxes. In other words, it is an informal sector of the economy that is almost beyond all statistical calculation, it hides profits and does not pay taxes. This sector includes small owners, individual entrepreneurs, farmers, seasonal and temporary workers, part-time workers, etc. Thus, illegal employment 
combines: the concealment of income (and, accordingly, employment) generated from legal activities, activity prohibited by law of the country.

The Copenhagen Declaration on Social Development recorded the responsibility of the leadership of the states and governments of the UN Member States to take account the crucial importance of the informal sector in employment development strategies in order to increase its contribution to overcoming unemployment and to social integration, and to strengthen its links with organized economic activity. This document confirms that the informal sector of the labour market is a full-fledged segment of socio-economic relations in society, the most important factor in ensuring employment and welfare of the population. However, there remain many "blank spots" in determining this sector's essence and nature of its interaction with the formal sector, in the method of determining its scale and evaluation of results. Determining the scope of the informal sector of the labour market is a very difficult task, which, in turn, creates barriers to identifying the main causes of its growth and the implementation of policies that would ensure the maximum public benefit from its functioning.

In the works devoted to the informal economy, there is a tendency to reduce the informality to the properties of the economic and social order of the Third World countries, whose poverty and poverty, the intensity of migratory flows as well as underdevelopment of civil and legal consciousness is a fertile ground for informal economic activity. There is a steady perception of the informal economy as a kind of dysfunction, for which the greater the scope of its functioning, the less developed the country is. Informal economy is a vestigial phenomenon of pre-industrial phase in the history of civilization, which also firmly connects its existence with the economic and social backwardness of the state. Recently, a new-institutional approach to the concept of informal economic activity appears to be the most popular in the scientific environment. Informal economic activity is considered as a way to reduce economic entity's expenditure by refusing formal rules of economic practice (the actions are not subject to the institutionalized rules of the game). Thus, in our opinion, it is possible to give the following definition to the concept of illegal (unregistered) employment: this is the employment of individuals within the permitted or forbidden by law economic activity, the results of which, for various reasons, are not taken into account by official statistics. The evaluation of the level for shadow employment and the shadow economy as a whole has not been made yet.

Consequently, the modern complex system of employment can be characterized as mixed, since in it, we can observe interaction between different forms of ownership (state and non-state) and different types of employment (basic, additional, registered, unregistered, etc.). Such versatile integration requires the development of an appropriate mechanism for regulating the employment of the population which takes into account all types and forms of employment. All three blocks of employment are in interaction and interconnection, as indicated by the presence of dotted lines in fig. 3. At the same time, each of the blocks can be categorized according to the types of employment of the other two blocks and vice versa (primary employment can be both registered and unregistered, as well as registered employment can be both primary and secondary).

In block 3 (see Fig. 3), unoccupied population forms the main subpopulation of shadow employment. Moreover, those who offered their labour services in the employment market but did not receive their recognition form the "involuntary unemployed population", or the actual stock of hired labour. Most of them are officially registered as "unemployed", including economically inactive population (pensioners, teenagers, invalids, and voluntarily unemployed people in working age). "Voluntary unpaid working-age population" consists of persons who: a) do not offer their labour services in the employment market because of low wages; however, they are ready to start working if wages are higher; b) they prefer not to work in general rather than be engaged in lowpaid work. In literature, such a phenomenon is sometimes defined as voluntary or passive unemployment. This definition seems to be inaccurate.

Unemployment is a situation in the economy in which a part of the able-bodied population becomes relatively redundant (the reserve army of labour). Unemployment refers to a complex socio-economic phenomenon, which is manifested in the discrepancy between the demand for labour and its supply in the employment market, as a result of which a part of the able-bodied population does not have a permanent job (earnings from work), thus replenishing not only the reserve army of labour, but the shadow sector of the economy.

In Ukraine, in accordance with the Law "On Employment of the Population", the unemployed are considered to be able-bodied citizens of working age, who, due to reasons independent of them, have no earnings (labour income) due to the lack of suitable work. These are registered in the State Employment Service, are really looking for work and able to start job. The unemployed (by definition of IOE (International Organization of Employers)) are individuals of working age, physically healthy, who do not work because of reasons that do not depend on them, are actively engaged in job search and are ready to proceed immediately to work. 
Sometimes an extended interpretation of the concept "unemployed" (as able-bodied population of working age unoccupied in the national economy) is inappropriate. It is because this concept includes both those who are actively seeking employment and those who are not seeking it, as well as persons who pretend to occupy paid work position, but do not seek to be in compliance with the professional qualification level, health status, internal self-discipline for the desired job, etc.

The economic potential of society is not fully involved because unemployed labour does not participate in the growth of national wealth. The dependence between the level of unemployment and the lagging of the actual gross national product (GNP) from the potential GNP is expressed in mathematical form in the so-called Okun's law. If the actual unemployment rate exceeds the natural one by $1 \%$, then the actual GNP lag from potential volumes is $2.5 \%$. This allows to calculate the absolute national product loss associated with any level of unemployment (Maslow, 1999).

It should be noted that such categories as hidden unemployment and shady employment can not be expressed through Okun's law, because they are inherent in our economic system. It is worth mentioning that official statistics do not keep records of these phenomena, but this is the underwater part of the employment "iceberg" in the domestic labour market, which is several times higher than the fixed unemployment rate. Due to hidden unemployment and shadow employment, the real unemployment rate is much higher, therefore, the extent of the actual GNP lag from the potential one in Ukraine is much higher (2.5\%). However, this is a problem for future research.

\section{Conclusions}

1. Study of the above concepts of labour resources shows that each of them, taken separately from the workforce as a system, can not characterize this system as a whole, since it plays a certain role in it. With the change in the value of one element, the value of the other changes accordingly. However, the presence of a number of elements that form the investigated whole, is not enough to determine the analysed object as a system. For this purpose, another important principle of the system must be preserved - the hierarchy of its structure, that is, the sequence of the inclusion of the lower-level system into a higher-level system. Such levels are macro-, meso- and micro-levels (i.e., labour markets of the country as a whole, of separate regions and settlements).

2. The next principle of the system is that its system-forming elements are in certain relations and connections to each other, thus forming a holistic object. Therefore, in studying the considered system a structure that determines the connection between elements and parts of the system is very important.

3. The whole organization of the system is based on certain structural relations of elements of subsystems and elements of the system. These structural relationships determine the properties and functions of the system under study as a whole and play an important role in the system. Performing various functions the effect of all these elements is ultimately subordinated to the achievement of the common aim - the efficient use of labour resources. The presence of a common ultimate goal also gives the right to consider labour resources as a systematic object of research.

\section{Appendix A. Supplementary material}

Supplementary data associated with this article can be found, in the online version, at https://dx.doi.org/10.14254/jems.2018.3-1.3

\section{Funding}

The authors received no direct funding for this research.

\section{Citation information}

Voit, S., Tkachenko, V., \& Oleshkevich, I. (2018). Intellectual potential as a means of reproduction and renewal of the unity of productive forces and industrial relations. Economics, Management and Sustainability, 3(1), 34-43. doi:10.14254/jems.2018.3-1.3.

\section{References}

Bulgakov, S.N. (1999). Philosophy of Economy. Moscow: Nov. Technology. [in Russian]

Great economic dictionary. (1999). Moscow: Bolshaya rossiyskaya entsiklopediya; Spb .: Norint. [in Russian]

Leskov, L.V. (2001). Knowledge and power. Synergetic Cryptology. Moscow: SINTEG. [in Russian] 
Lyashenko, V.I. (2006). Regulation of the development of economic systems: theory, regimes, institutes. Donetsk: DonNTU. [in Ukrainian]

Maslow, A.H. (1999). Motivation and personality. Moscow-SPb.: Eurasia. [in Russian]

Nagornyak, G., \& Vovk, Yu. (2012). The role of the state innovation policy to ensure economic development of Ukraine. Socio-Economic Problems and the State, 6(1), 202-209. [in Ukrainian]

Tkachenko, V.A. (2007). In search of a new paradigm of social development relations. Bulletin of Economic Science of Ukraine, 1(7), 159-164. [in Ukrainian]

Tkachenko, V.A. (2008). Intellectual potential in the basis of development of production forces and industrial relations. Dnipro: DUAN, MONOLIT. [in Ukrainian]

Tugan-Baranovsky, M.I. (1994). Political economy: popular Course. Kyiv: Scientific thought. [in Ukrainian]

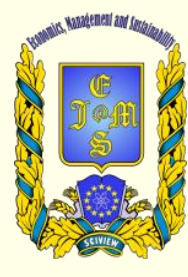

(C) 2016-2018, Economics, Management and Sustainability. All rights reserved.

This open access article is distributed under a Creative Commons Attribution (CC-BY) 4.0 license.

You are free to:

Share - copy and redistribute the material in any medium or format Adapt - remix, transform, and build upon the material for any purpose, even commercially.

The licensor cannot revoke these freedoms as long as you follow the license terms.

Under the following terms:

Attribution - You must give appropriate credit, provide a link to the license, and indicate if changes were made.

You may do so in any reasonable manner, but not in any way that suggests the licensor endorses you or your use.

No additional restrictions

You may not apply legal terms or technological measures that legally restrict others from doing anything the license permits.

Economics, Management and Sustainability (ISSN: 2520-6303) is published by Scientific Publishing House "CSR", Poland, EU and Scientific Publishing House "SciView", Poland

Publishing with JEMS ensures:

- Immediate, universal access to your article on publication

- High visibility and discoverability via the JEMS website

- Rapid publication

- Guaranteed legacy preservation of your article

- Discounts and waivers for authors in developing regions

Submit your manuscript to a JEMS at http://jems.sciview.net or submit.jems@sciview.net 